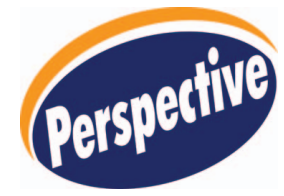

Jes Focus Issue on Proton Exchange Membrane Fuel Cell (PEMFC) Durability

\title{
Prospects for Durable Hydrocarbon-Based Fuel Cell Membranes
}

\author{
Lorenz Gubler, $\oplus^{1, *, z}$ Thomas Nauser, ${ }^{2}$ Frank D. Coms, ${ }^{3}{ }^{3}$ Yeh-Hung Lai, ${ }^{3}$ \\ and Craig S. Gittleman ${ }^{3, z}$ \\ ${ }^{1}$ Electrochemistry Laboratory, Paul Scherrer Institut, 5232 Villigen PSI, Switzerland \\ ${ }^{2}$ Laboratory of Inorganic Chemistry, ETH Zürich, 8093 Zürich, Switzerland \\ ${ }^{3}$ General Motors Global Proplusion Systems, Pontiac, Michigan, 48340 USA
}

\begin{abstract}
Various types of hydrocarbon-based ionomer membranes have been proposed for application in fuel cells as an alternative to perfluoroalkylsulfonic acid (PFSA) membranes. The issue of chemical and mechanical degradation of this class of ionomer membranes and the combination thereof, especially under automotive operating conditions, has not been fully resolved at present. Here, we highlight key degradation mechanisms of hydrocarbon-based membranes in the fuel cell and identify necessary developments to mitigate radical induced membrane degradation and mechanical shortcomings of this class of ionomers that may enable them to compete with and, possibly, replace PFSA membranes.

(C) The Author(s) 2018. Published by ECS. This is an open access article distributed under the terms of the Creative Commons Attribution 4.0 License (CC BY, http://creativecommons.org/licenses/by/4.0/), which permits unrestricted reuse of the work in any medium, provided the original work is properly cited. [DOI: 10.1149/2.0131806jes]

(cc) BY
\end{abstract}

Manuscript submitted December 5, 2017; revised manuscript received February 22, 2018. Published March 6, 2018. This paper is part of the JES Focus Issue on Proton Exchange Membrane Fuel Cell (PEMFC) Durability.

Fuel cells are clean and efficient electrochemical energy conversion devices that have found application in combined heat and power units ${ }^{1}$ and forklifts for materials handling markets. ${ }^{2}$ The polymer electrolyte fuel cell (PEFC) fueled by hydrogen is particularly attractive for applications with variable load profile and intermittent operation and is therefore considered as a power source for automotive drivetrains. Fuel cell electric vehicles are on the market today, yet production is limited to around 1000 units per year. For wide-scale commercialization, cost must be reduced significantly without compromising power density, efficiency, reliability and durability.

\section{Current Status}

One of the critical components of the PEFC in terms of performance and durability is the proton exchange membrane (PEM) used as polymer electrolyte. The state-of-the-art PEFCs utilize perfluoroalkylsulfonic acid (PFSA) membranes, e.g., Nafion, Flemion, Aquivion, etc. For automotive applications, membranes have a typical thickness below $20 \mu \mathrm{m}$ to minimize ohmic losses. To be commercially viable, the membrane must survive 12 years in a vehicle and $8000 \mathrm{~h}$ of operation including transient operation with start/stop and freeze/thaw cycles. ${ }^{3}$ Significant advances have been made over the past decade in the understanding and improvement of PFSA membrane durability. The membranes used today are end-group stabilized, mechanically reinforced, e.g., using a porous expanded polytetrafluoroethylene (ePTFE) support, and doped with antioxidants, such as cerium or manganese based additives, to improve the mechanical and chemical robustness of the material.

Hydrocarbon-based PEMs are the most diverse class of materials studied for fuel cell application. ${ }^{4}$ Typical hydrocarbon ionomers are thermally stable polymers that contain aromatic units in the main chain, which may be linked by a variety of functional groups (Figure 1a). They are of high interest because of their expected lower cost, intrinsically lower gas $\left(\mathrm{H}_{2}, \mathrm{O}_{2}, \mathrm{~N}_{2}\right)$ permeability, and higher glass transition temperatures compared to PFSA membranes. ${ }^{5}$ The lower reactant permeability in particular is extremely attractive: on the one hand, it enables higher fuel efficiency and can enable use of yet thinner membranes, which in turn leads to cost reduction and increased power density. On the other hand, the lower gas permeability leads to a lower radical formation rate through reaction of $\mathrm{H}_{2}$ and $\mathrm{O}_{2}$ on the catalyst surface. It has to be mentioned that the desire for low

*Electrochemical Society Member.

${ }^{\text {z} E-m a i l: ~ l o r e n z . g u b l e r @ p s i . c h ; ~ c r a i g . g i t t l e m a n @ g m . c o m ~}$ gas permeability does not apply to the ionomer in the catalyst layer, as high gas permeability is required here. The versatile chemistry of these materials provides design flexibility and offers the prospect of tailoring membrane chemistry and architecture to specific requirements. The challenge of low ionic conductivity of hydrocarbon membranes, in particular at relative humidities below $50 \%$, can be successfully addressed to close the gap to the conductivity of PFSA membranes by a dedicated design of the polymer architecture, i.e., using multiblock copolymers. ${ }^{6}$ One of the main shortcomings of this membrane class, however, is its intrinsic susceptibility to radical induced chain degradation and the gradual embrittlement of the membrane, which is related to the chemical changes of the polymer. ${ }^{7}$ In this perspective article, we discuss approaches and prospects for mitigating chemical and mechanical degradation of hydrocarbon- and non-perfluorinatedbased PEMs, considering the specific mechanisms at play in this class of ionomer materials.

\section{Future Needs and Prospects}

Chemical Stability.-Under the operating conditions of a PEFC, the radical species $\mathrm{HO}^{\bullet}, \mathrm{H}^{\bullet}$ and $\mathrm{HOO}^{\bullet}$ form as a result of the presence of $\mathrm{H}_{2}, \mathrm{O}_{2}$ and the noble metal catalyst. ${ }^{8}$ The hydroxyl radical $\left(\mathrm{HO}^{\bullet}\right)$ is particularly harmful and represents the major source of oxidative degradation in the PEFC. Although PFSA ionomers display excellent chemical stability, they are not immune to degradation. $\mathrm{HO}^{\bullet}$ attacks weak points of the PFSA chain, which leads to chain unzipping and mid-point chain scission. ${ }^{9}$ This process is relatively slow and the half-life of $\mathrm{HO}^{\bullet}$ in a water-swollen PFSA ionomer is on the order of microseconds, which makes it possible for suitable radical scavengers, such as $\mathrm{Ce}^{3+}$ and $\mathrm{Mn}^{2+}$, to quench $\mathrm{HO}^{\bullet}$ with a high yield $(99 \%$ for a cerium-ion concentration of $0.1 \mathrm{M}$ ) and thus mitigate radical attack on the PFSA ionomer. ${ }^{10} \mathrm{~A}$ key feature of these metal ions is that, once oxidized, they can be reduced again by $\mathrm{H}_{2} \mathrm{O}_{2}$ present in the MEA, thus establishing a catalytic radical scavenging scheme, whereby the scavenger is constantly regenerated. ${ }^{10,11}$

The situation is rather different in the case of a hydrocarbon-based ionomer. The rate constant for the reaction of $\mathrm{HO}^{\bullet}$ with aromatic units is on the order of $10^{9}$ to $10^{10} \mathrm{M}^{-1} \mathrm{~s}^{-1}$. ${ }^{12}$ In a coiled, waterswollen polymer, it may be an order of magnitude lower. ${ }^{13}$ Considering the high concentration of aromatic units of around $1 \mathrm{M}$, this leads to a half-life of $\mathrm{HO}^{\bullet}$ in the range of nanoseconds. Given that the rate constant for the reaction of $\mathrm{HO}^{\bullet}$ with $\mathrm{Ce}^{3+}$, the most effective scavenger known in the fuel cell literature, is $3 \cdot 10^{8} \mathrm{M}^{-1} \mathrm{~s}^{-1}$ (at room temperature), ${ }^{12}$ and the $\mathrm{Ce}^{3+}$ concentration is unlikely to be higher 

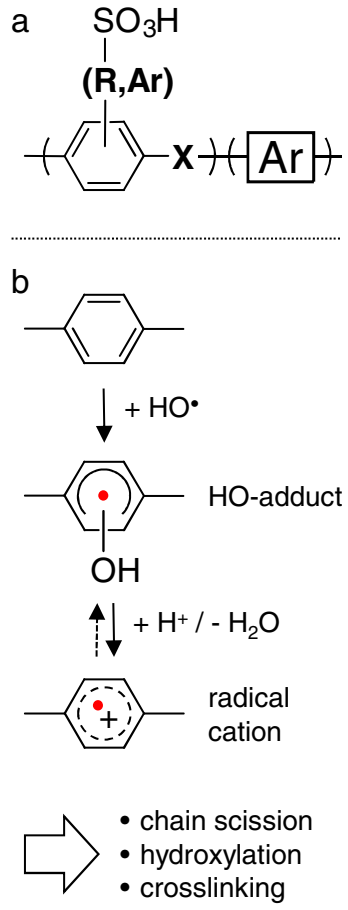

Figure 1. a, Schematic structure of sulfonated hydrocarbon-based proton exchange membranes, encompassing a large number of variations. The main chain consists of arylene (Ar) units. The sulfonic acid group is located on the main chain or a pendant chain, which may be itself aromatic (Ar), aliphatic $(\mathrm{R})$, or a mixture thereof. The primary mechanism of $\mathrm{HO}^{\bullet}$ attack on aromatic compounds is by addition to the ring. The formed HO-adduct can undergo reversible acid-catalyzed water elimination and thus collapse to the radical cation. Various end products of $\mathrm{HO}^{\bullet}$ attack are indicated (adapted from Ref. $50)$.

than $0.1 \mathrm{M}$, the associated half-life of $\mathrm{HO}^{\bullet}$ of $\sim 20 \mathrm{~ns}$ is by far not low enough to scavenge significant fractions of $\mathrm{HO}^{\bullet}$, say $80 \%$ or more, which would provide a $>5 \mathrm{x}$ lifetime extension. Therefore, other antioxidant strategies need to be devised.

One approach is again based on the use of a radical scavenger. Yet to scavenge $80 \%$ of $\mathrm{HO}^{\bullet}$ or more, the rate constant needs to be much higher, i.e. in the range of $10^{10} \mathrm{M}^{-1} \mathrm{~s}^{-1}$ if we assume a scavenger concentration of $0.1 \mathrm{M}$. Such high rates can only be provided by aromatic type antioxidants, such as phenol or derivatives thereof. ${ }^{14}$ Still, scavenging $>80 \%$ of $\mathrm{HO}^{\circ}$ is challenging. In addition, and this is probably the more difficult task, the scavenger should be amenable to regeneration. However, there is no such example at the moment, as the thermodynamics and kinetics of regeneration by $\mathrm{H}_{2} \mathrm{O}_{2}$ are unfavorable. ${ }^{7}$ Phenol type antioxidants are depleted over time as they themselves undergo oxidative aging. Furthermore, antioxidant functionalities need to be immobilized within the ionomer structure to avoid leaching out over time.

Therefore, we probably cannot prevent hydrocarbon-based PEMs from being attacked by $\mathrm{HO}^{\bullet}$. The question then is, what types of intermediate are formed upon radical attack and what are associated follow-up reactions? $\mathrm{HO}^{\bullet}$ reacts with an aromatic hydrocarbon substrate primarily by addition to the ring, forming an $\mathrm{OH}$-adduct (Figure $1 \mathrm{~b}$ ). ${ }^{15}$ At low $\mathrm{pH}$, acid catalyzed water elimination may take place, which yields the radical cation. The intermediates may trigger chain scission reactions. The exact mechanism and kinetics depend on the chain chemistry, the nature of the linking groups $\mathrm{X}$ and other substituents (electron donating or withdrawing), and the steric configuration. In any case, $\mathrm{HO}^{\bullet}$ attack on hydrocarbon polymers triggers chain oxidation, which may also lead to cross-linking reactions and altered crystallization properties. ${ }^{16}$ Even though those latter mechanisms do not necessarily cause chain breakdown, the irreversible aging of the polymer causes a deterioration of the chemical and mechanical integrity of the membrane, which ultimately leads to failure of the component and cell.

Some intermediates may be sufficiently long lived such that ionomer repair reactions may be conceivable. A possible repair reaction could be the reaction of an intermediate with $\mathrm{H}_{2} \mathrm{O}_{2}{ }^{7}$ The challenge here would be to stabilize intermediates for sufficient time (milliseconds range) to allow the reaction with $\mathrm{H}_{2} \mathrm{O}_{2}$ to take place. The properties of the intermediate, such as redox potential and reactivity, may be tuned through the substituent pattern of the aromatic ring. Also, clustering in the polymer coil and steric hindrance effects increase lifetime. Unfortunately, however, reactions involving $\mathrm{H}_{2} \mathrm{O}_{2}$ are generally rather slow and the concentration of $\mathrm{H}_{2} \mathrm{O}_{2}$ in the membrane is usually below $1 \mathrm{mM}$.

In a further approach damage transfer from the polymer to a mediator may be envisioned. A compound of suitable chemistry and redox potential, which could be incorporated into the ionomer at much higher concentration than $\mathrm{H}_{2} \mathrm{O}_{2}$, say, $0.1 \mathrm{M}$, would mediate the repair and regeneration reactions. Compared to the direct repair by $\mathrm{H}_{2} \mathrm{O}_{2}$, the requirement for the minimum rate constant of the reaction of the mediator with the polymer intermediate would by considerably relaxed. The mediator itself would then need to be repaired. Obviously, for this to work, the chemistry of the polymer and the mediator needs to be adequately adjusted and side-reactions, e.g., the reaction of the mediator with $\mathrm{HO}^{\bullet}$, minimized. Redox potentials of the polymer and mediator have to be carefully tuned, and the reaction kinetics have to be fast enough to maximize the yield of the damage transfer reaction. Furthermore, additives incorporated into the membrane merely by doping may move and be leached out over time. ${ }^{17}$ Tethering of the functional motifs to the polymer chain or an inorganic filler may be a promising approach for immobilization.

Mechanical durability.-Mechanical degradation of PEMs caused by humidity cycling in an operating fuel cell is a well-documented failure mode. Mechanical membrane lifetime is generally evaluated by humidity cycling tests, where gas feeds are cycled between dry and supersaturated air or $\mathrm{N}_{2}$ at elevated temperatures. ${ }^{18,19}$ The failure is driven by fatigue caused by repeated transitions between wet and dry conditions, where compressive stresses build as the membrane swells in a constrained cell, followed by tensile stresses generated during membrane drying. The magnitude of these stresses depends on many factors including (1) membrane hygral expansion, (2) membrane modulus at different humidity conditions, (3) rates of wetting and drying, (4) magnitude of the humidity swing and (5) duration spent and wet and dry conditions.

There are several attributes of hydrocarbon membranes that tend to make them susceptible to greater stresses during humidity cycling than PFSA membranes. In general, hydrocarbon membranes such as sulfonated polyarylenes with ketone or sulfone linkers tend to adsorb more water than PFSA membranes with comparable IECs. ${ }^{20}$ Also, hydrocarbon PEMs tend to be significantly stiffer than PFSA membranes. ${ }^{21,22}$ While this is often touted as an advantage in the literature as stiffer membranes swell less when humidified, a higher modulus, particularly at dry conditions when tensile stresses are generated, actually leads to greater stresses during humidity cycling and, thus, shorter life. There have been several studies of the stress profiles generated during humidity cycling of PFSA membranes using various types of viscoelastic and viscoplastic models. ${ }^{23-30}$ However, there have been few studies on the stress profiles of hydrocarbon membranes during humidity cycling. Wright et al. developed a non-linear viscoelastic-viscoplastic stress model for a sulfonated perfluorocyclobutane (sPFCB) membrane blended with polyvinylidene difluoride (PVDF) ${ }^{31}$ Finlay et al. used a linear viscoelastic stress model ${ }^{26}$ to create stress profiles during humidity cycling (Figure 2), which showed that the tensile stress generated during the dry part of the cycles is more than 3 times greater for the sPFCB than for several commercial PFSA membranes. 32

The higher stresses experienced by hydrocarbon membranes can be partially mitigated by effective polymer structure design. For example, block polymers with lamellar structures have been shown to 


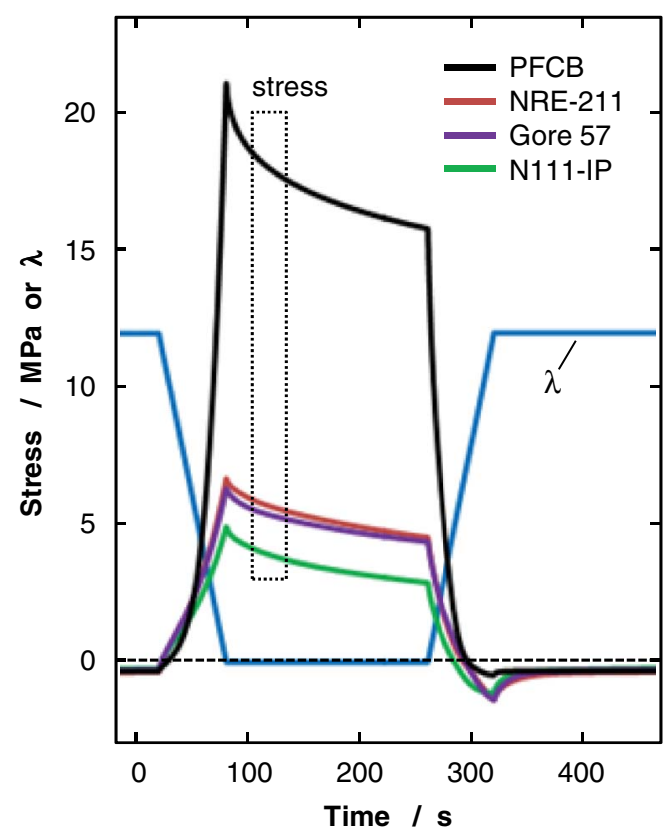

Figure 2. Comparison of simulated membrane stress histories of three PFSA (Nafion NRE211, Nafion N111-IP, and GoreSelect 57) membranes and a hydrocarbon (PFCB/PVDF with 70:30 wt:wt blend) membrane subjected to the same history of water content from $\lambda\left(\mathrm{H}_{2} \mathrm{O} / \mathrm{SO}_{3} \mathrm{H}\right)$ of 0-12 (from Ref. 32).

exhibit advantageous anisotropic swelling. McGrath and Baird have shown that certain polyarylene multi-block copolymer PEMs swell preferably in the thickness direction, whereas random copolymers swell isotropically. ${ }^{33}$ Such lower in-plane swelling reduces stresses caused by RH cycling. In general, the block copolymers also tend to adsorb less water than random copolymers. ${ }^{4,6}$ Gross et al. showed that sulfonated poly(arylene ether) block copolymers exhibited 10-100 times longer lifetime in RH cycling tests than random copolymers, with triblock copolymers with short range order (tens of nm) having longer lifetimes than those with long range order (hundreds of $\mathrm{nm}){ }^{4}$ Ishikawa et al. have shown that the nature of the hydrophilic block in semi-block copolymers can significantly impact the mechanical membrane durability. ${ }^{34}$ In their study a sulfonated poly(phenylene) (SPP) membrane had a 5-fold longer life in the US Department of Energy wet-dry cycling test compared to a sulfonated poly(arylene ether ketone) membrane. This was attributed to 2-fold higher stiffness due to the rigid structure of the SPP, leading to $50 \%$ lower swelling. Such high stiffness does, however, lead to greater tensile stresses during membrane drying. Thus, approaches to tailor polymer structure alone do not enable sufficient mechanical durability for automotive applications. In all of these studies, the homogeneous polyarylene membranes started leaking at or before the 20,000 RH cycle target, which is much earlier than state-of-the-art PFSA membranes. ${ }^{35}$

In addition to the stresses generated during humidity cycling, mechanical membrane durability also strongly depends on membrane strength. Historically, one challenge of hydrocarbon membranes is their brittleness, especially in the dry state, ${ }^{36,37}$ relative to the highly elastic PFSA membranes which have a highly flexible, yet tough PTFE backbone. Nearly all available hydrocarbon PEMs contain aromatic backbones which lead to their inherent stiffness and low fracture energies. Such brittleness can be alleviated by blending or copolymerizing with elastomers such as PVDF ${ }^{38-40}$ cross-linking ${ }^{41-43}$ or increasing the ionomer molecular weight. ${ }^{44}$

Effective approaches for mitigating mechanical membrane damage in PFSA membranes have been applied to hydrocarbons; including the development of composite membranes which contain non-conductive species which serve to both reduce membrane swelling and increase fracture resistance. One common approach is incorporation of a porous polymer reinforcing layer, such as ePTFE or stiffer polymers. ${ }^{45-47}$ Zou et al. showed that ePTFE-supported SPFCB membranes ran for over $3000 \mathrm{~h}$ in an accelerated durability test before ultimately failing due to chemical rather than mechanical degradation. ${ }^{48}$ To date, most of these approaches as applied to hydrocarbon PEMs have not been proven in RH cycling tests. There have been attempts to reinforce hydrocarbon membranes with conductive materials to avoid the performance penalty induced by adding non-conductive materials. For example, Oh et al. were able to double the lifetime in wet-dry cycling tests without compromising performance by adding $0.3 \mathrm{wt} \%$ functionalized 2D boron nitride nanoflakes to sPEEK membranes, yet still only achieved $1000 \mathrm{RH}$ cycles. ${ }^{49}$ In order to enable mechanical durability of hydrocarbon membranes, a combination of approaches including tailored block copolymer structures and composite membrane designs is required.

\section{Conclusions}

The shortcomings related to the mechanical durability of hydrocarbon membranes should be addressed using approaches that both reduce the membrane stress during humidity cycling and increase the strength at dry conditions, for instance by minimizing in-plane swelling via clever multi-block copolymer architectures and lowering membrane stiffness by blending or copolymerizing with elastomeric polymers. The most effective approach is to simultaneously reduce inplane swelling and increase strength by using a relatively stiff porous polymer support. Tackling radical induced degradation will require a dedicated antioxidant strategy, which will likely focus on repairing intermediates formed upon radical attack, because quenching of radicals by scavenging is too slow. Also, the protection mechanism needs to be self-sustaining over thousands of operating hours. Moreover, mitigation mechanisms for chemical and mechanical degradation should be mutually compatible. The prospect of membranes with up to ten times reduced gas crossover justifies the concerted development effort required for hydrocarbon membranes to become suitable alternatives to perfluorinated fuel cell membranes.

\section{ORCID}

Lorenz Gubler (1) https://orcid.org/0000-0002-8338-6994

Frank D. Coms (D) https://orcid.org/0000-0002-4916-0350

\section{References}

1. I. Staffel, M. Matian, D. J. L. Brett, N. P. Brandon, and A. D. Hawkes, in Domestic Microgeneration - Renewable and Distributed Energy Technologies, Policies and Economics, I. Staffel, D. J. L. Brett, N. P. Brandon, and A. D. Hawkes (Editors), p. 219, Routledge (2015)

2. J. P. Meyers, Electrochem. Soc. Interf., 17, 36 (2008).

3. R. Borup, J. Meyers, B. Pivovar, Y. S. Kim, R. Mukundan, N. Garland, D. Myers, M. Wilson, F. Garzon, D. Wook, P. Zelenay, K. More, K. Stroh, T. Zawodzinski, J. Boncella, J. E. McGrath, M. Inaba, K. Miyatake, M. Hori, K. Ota, Z. Ogumi, S. Miyata, A. Nishikata, Z. Siroma, Y. Uchimoto, K. Yasuda, K.-i. Kimijima, and N. Iwashita, Chem. Rev., 107, 3904 (2007).

4. M. Gross, G. Maier, T. Fuller, S. MacKinnon, and C. Gittleman, in Handbook of Fuel Cells, Volume 5, W. Vielstich, H. A. Gasteiger, and H. Yokokawa (Editors), p. 283, Wiley-VCH, Chichester, United Kingdom (2009).

5. F. Wang, M. Hickner, Y. S. Kim, T. A. Zawodzinski, and J. E. McGrath, J. Membr. Sci., 197, 231 (2002).

6. X. Yu, A. Roy, S. Dunn, A. S. Badami, J. Yang, A. S. Good, and J. E. McGrath, J. Polym. Sci., Part A: Polym. Chem., 47, 1038 (2009).

7. L. Gubler and W. H. Koppenol, in The Chemistry of Membranes Used in Fuel Cells: Degradation and Stabilization, S. Schlick (Editor), p. 107, Wiley, Hoboken (2018).

8. M. Danilczuk, F. D. Coms, and S. Schlick, J. Phys. Chem. B, 113, 8031 (2009).

9. F. D. Coms, ECS Trans., 16, 235 (2008).

10. F. D. Coms, H. Liu, and J. E. Owejan, ECS Trans., 16, 1735 (2008)

11. L. Gubler and W. H. Koppenol, J. Electrochem. Soc., 159, B211 (2012)

12. G. V. Buxton, C. L. Greenstock, W. P. Helman, and A. B. Ross, J. Phys. Chem. Ref. Data 17, 513 (1988).

13. Y. K. Bhardwaj, H. Mohan, S. Sabharwal, and T. Mukherjee, Radiat. Phys. Chem., 62, 229 (2001).

14. L. R. C. Barclay and M. R. Vinqvist, in The Chemistry of Phenols, Z. Rappoport (Editor), p. 839, John Wiley \& Sons Ltd., Chichester (2003). 
15. G. Hübner and E. Roduner, J. Mater. Chem., 9, 409 (1999).

16. N. Grassie and G. Scott, Polymer Degradation and Stabilization, Cambridge University Press (1985).

17. F. D. Coms, S. Schlick, and M. Danilczuk, in The Chemistry of Membranes Used in Fuel Cells: Degradation and Stabilization, S. Schlick (Editor), p. 75, Wiley, Hoboken (2018).

18. M. F. Mathias, R. Makharia, H. A. Gasteiger, J. H. Conley, T. J. Fuller, C. J. Gittleman, S. S. Kocha, D. P. Miller, C. K. Mittelstaedt, T. Xie, S. G. Yan, and P. T. Yu, Electrochem. Soc. Interf., 14, 24 (2005).

19. Y.-H. Lai, C. K. Mittelsteadt, C. S. Gittleman, and D. A. Dillard, in ASME 2005 3rd International Conference of Fuel Cell Science, Engineering and Technology, p. FUELCELL2005, Ypsilanti, Michigan, USA (2005).

20. B. Yang and A. Manthiram, Electrochem. Solid-State Lett., 6, A229 (2003).

21. I. A. Hussein and S. M. J. Zaidi, in Polymer Membranes for Fuel Cells, S. M. J. Zaid and T. Matsuura (Editors), p. 235, Springer Science+Business Media, LLC (2009).

22. J. Miyake and K. Miyatake, Polym. J., 49, 487 (2017).

23. Y. Tang, M. H. Santare, A. M. Karlsson, S. Cleghorn, and W. B. Johnson, J. Fuel Cell Sci. Technol., 3, 119 (2006).

24. A. Kusoglu, A. M. Karlsson, M. H. Santare, S. Cleghorn, and W. B. Johnson, J. Power Sources, 161, 987 (2006).

25. A. Kusoglu, M. H. Santare, A. M. Karlsson, S. Cleghorn, and W. B. Johnson, J. Electrochem. Soc., 157, B705 (2010).

26. Y.-H. Lai, C. K. Mittelsteadt, C. S. Gittleman, and D. A. Dillard, J. Fuel Cell Sci. Technol., 6 (2009).

27. N. S. Khattra, A. M. Karlsson, M. H. Santare, P. Walsh, and F. C. Busby, J. Power Sources, 214, 365 (2012).

28. R. Solasi, Y. Zou, X. Huang, and K. Reifsnider, Mech. Time-Depend. Mater, 12, 15 (2008).

29. M. N. Silberstein and M. C. Boyce, J. Power Sources, 196, 3452 (2011)

30. A. Kusoglu, Y. Tang, M. Lugo, A. M. Karlsson, M. H. Santare, S. Cleghorn, and W. B. Johnson, J. Power Sources, 195, 483 (2010).

31. J. A. Wright, M. W. Ellis, D. A. Dillard, S. W. Case, R. B. Moore, Y. Li, Y.-H. Lai, and C. S. Gittleman, Proceedings of the ASME International Mechanical Engineering Congress and Exposition (IMECE), 8, 347 (2012).

32. K. A. Finlay, Characterization of Sulfonated Perfluorocyclobutane/Poly(Vinylidene Difluoride) (PFCB/PVDF) Blends for Use as Proton Exchange Membranes, PhD
Thesis, Virginia Polytechnic Institute and State University, Blacksburg, VA, USA (2012).

33. J. E. McGrath and D. G. Baird, DOE Hydrogen Program FY 2008 Progress Report (2008), p. 982, https://www.hydrogen.energy.gov/pdfs/progress08/ v_g_9_mcgrath.pdf.

34. H. Ishikawa, Y. Fujita, J. Tsuji, M. Kusakabe, J. Miyake, Y. Sugawara, K. Miyatake, and M. Uchida, J. Electrochem. Soc., 164, F1204 (2017).

35. C. S. Gittleman, F. D. Coms, and Y.-H. Lai, in Polymer Electrolyte Fuel Cell Degradation, M. M. Mench, E. C. Kumbur, and T. N. Veziroglu (Editors), p. 15, Academic Press, Boston (2012)

36. K. D. Kreuer, in Handbook of Fuel Cells, John Wiley \& Sons, Ltd (2010).

37. S. M. MacKinnon, T. J. Fuller, F. D. Coms, M. R. Schoeneweiss, C. S. Gittleman, Y. H. Lai, R. Jiang, and A. M. Brenner, in Encyclopedia of Electrochemical Power Sources, J. Garche (Editor), p. 741, Elsevier, Amsterdam (2009).

38. R. Jiang, T. Fuller, S. Brawn, and C. Gittleman, Electrochim. Acta, 110, 306 (2013).

39. Y. Fu, A. Manthiram, and M. D. Guiver, Electrochem. Commun., 8, 1386 (2006).

40. C. M. Gibon, S. Norvez, S. Tencé-Girault, and J. T. Goldbach, Macromolecules, $\mathbf{4 1}$ 5744 (2008)

41. J. A. Kerres, Fuel Cells, 5, 230 (2005)

42. H. B. Park, C. H. Lee, J. Y. Sohn, Y. M. Lee, B. D. Freeman, and H. J. Kim, J. Membr. Sci., 285, 432 (2006).

43. S. Zhong, X. Cui, H. Cai, T. Fu, C. Zhao, and H. Na, J. Power Sources, 164, 65 (2007).

44. T. Higashihara, K. Matsumoto, and M. Ueda, Polymer, 50, 5341 (2009)

45. S. Cleghorn, J. Kolde, and W. Liu, in Handbook of Fuel Cells, Volume 3, W. Vielstich, H. A. Gasteiger, and H. Yokokawa (Editors), p. 566, Wiley, Chichester, United Kingdom (2009).

46. F. Liu, B. Yi, D. Xing, J. Yu, and H. Zhang, J. Membr. Sci., 212, 213 (2003)

47. Fuel Cells Bulletin, 2016, 11 (2016)

48. L. Zou, T. Fuller, S. MacKinnon, and C. S. Gittleman, in Proc. Fall ACS National Meeting (2011)

49. K.-H. Oh, D. Lee, M.-J. Choo, K. H. Park, S. Jeon, S. H. Hong, J.-K. Park, and J. W. Choi, ACS Appl. Mater. Interfaces, 6, 7751 (2014).

50. M. Jonsson, in Radiation Chemistry. Present Status and Future Trends, C. D. Jonah and B. S. M. Rao (Editors), p. 319, Elsevier, Amsterdam a.o. (2001). 